\title{
Implementasi Agile Scrum Dengan Menggunakan Trello Sebagai Manajemen Proyek Di PT Andromedia
}

\author{
Afrisco Ardytia Febrian Amarta ${ }^{1 *}$, Indra Gita Anugrah ${ }^{2}$ \\ ${ }^{1,2}$ Universitas Muhammadiyah Gresik \\ Jl. Sumatera No. 101, Gresik 61121 \\ Corresponding author‘s e-mail: afriscoardytia@gmail.com ${ }^{1}$, indragitaanugrah@umg.ac.id ${ }^{2}$
}

\begin{abstract}
Abstrak - Pengembangan software erat kaitannya dengan rangkaian proses SDLC (Software Development Lifecycle). Dalam penerapan SDLC ada beberapa metodologi yang bisa diterapkan seperti waterfall dan agile. Waterfall merupakan suatu metodologi yang tahapan-tahapannya dilakukan secara berurutan. Hal ini menjadi sebuah kendala di metode waterfall jika terdapat perubahan requirement atau kebutuhan di tengah proses pengembangan. Berbeda dengan agile dimana tahapan-tahapannya dilakukan secara iteratif atau berulang. Namun dalam penerapannya membutuhkan kerangka kerja yang mendukung konsep agile, salah satunya adalah scrum. Dalam penerapan agile scrum membutuhkan alat yang bisa berfungsi sebagai kolaborasi antar anggota tim serta pencatatan manajemen proyek. Salah satu alat yang bisa digunakan adalah trello.
\end{abstract}

Kata kunci: SDLC, Agile, Scrum, Trello, Manajemen Proyek

Abstract - Software development is closely related to the SDLC (Software Development Lifecycle) process chain. Several methodologies can be applied in implementing the SDLC, such as waterfall and agile. The waterfall is a methodology whose stages are carried out sequentially. This becomes an obstacle in the waterfall method if there is a change in needs or needs in the middle of the development process. In contrast to agile where the stages are carried out iteratively or repeatedly. However, its implementation requires a framework that supports agile concepts, one of which is scrum. In implementing agile scrum, you need a tool that can work as a collaboration between team members and project management records. One tool that can be used is Trello.

Keyword : SDLC, Agile, Scrum, Trello, Manajemen Proyek

\section{Pendahuluan}

Pengembangan sebuah software atau aplikasi erat kaitannya dengan rangkaian proses SDLC (Software Development Lifecycle). SDLC merupakan siklus hidup pengembangan sebuah sistem[1]. SDLC secara umum mempunyai beberapa tahapan yaitu analisis kebutuhan, desain sistem, implementasi, testing, perilisan dan pemeliharaan. Dalam penerapan SDLC terdapat beberapa metodologi yang bisa diterapkan, diantaranya adalah waterfall dan agile[2].

Metode waterfall memiliki tahapan-tahapan yang di implementasikan secara berurutan, artinya sebuah tahapan tidak bisa dilakukan sebelum tahapan sebelumya selesai[3]. Ini menjadi sebuah kelemahan metode waterfall jika terdapat perubahan requirement atau kebutuhan disaat rangkaian proses pengembangan software sudah berjalan. Jika itu terjadi maka rangkaian proses akan dimulai dari awal kembali mengikuti konsep metode waterfall yang berurutan[4]. Hal ini akan menghambat proses development software secara kesuluruhan.

Berbeda dengan konsep metode waterfall, agile berbasis pada iterative dan incremental model[5]. Agile memisahkan siklus hidup pengembangan proyek menjadi sprint yang artinya disisi lain dapat dilihat sebagai kumpulan dari proyek kecil yang berbeda. Metode agile cukup fleksibel dan memungkinkan untuk membuat perubahan pada persyaratan, bahkan setelah perencanaan awal selesai[6]. Oleh karena itu metode agile dapat mengembangkan perangkat lunak yang memiliki requirement yang mudah berubah dengan cepat.

Namun, agile hanyalah sebuah metode yang berisi sebuah prinsip untuk mewujudkan penyelesaian masalah secara adaptif, maka dari itu dibutuhkanlah sebuah kerangka kerja yang membuat prinsip agile tersebut berwujud menjadi langkah-langkah, hal ini bisa dilakukan dengan menggunakan kerangka kerja scrum[7]. Hal yang penting di dalam scrum adalah sprint. Sprint ialah kegiatan yang memiliki durasi maksimal 30 hari yang terdiri dari beberapa aktifitas yaitu, sprint planning, daily scrum, sprint review dan sprint retrospective[8]. Agar aktifitas tersebut berjalan lancar dibutuhkanlah sebuah alat untuk kolaborasi tim, salah satu yang bisa mengakomodir itu adalah trello. Trello juga bisa berfungsi sebagai alat manajemen proyek di dalam metode agile scrum ini seperti pencatatan product backlog, sprint backlog dll.

Penerapan metode agile scrum ini sesuai dengan kebutuhan PT Andromedia jika mengerjakan proyek yang requirement atau kebutuhannya bisa berubah dengan cepat pada saat proses pengembangan software sudah berjalan. PT Andromedia merupakan perusahaan yang bergerak di bidang IT Consultant, dimana hal yang sering dilakukan adalah membuat software atau perangkat lunak untuk memenuhi kebutuhan klien. Tentunya 
permasalahan seperti perubahan requirement atau kebutuhan di tengah proses pengembangan software sangat memungkinkan terjadi. Dengan penerapan metode agile scrum menggunakan trello sebagai manajemen proyek ini diharapkan mampu menjawab kebutuhan di PT Andromedia.

\section{Tinjauan Pustaka}

2.1. Software Development Lifecycle

Software Development Lifecycle atau SDLC adalah rangkaian proses pembuatan dan pengubahan sistem serta model dan metodologi yang digunakan untuk mengembangkan sistem rekayasa perangkat lunak[9]. SDLC mempunyai beberapa tahapan seperti:

1. Analisis Kebutuhan

Tahapan analisis kebutuhan merupakan tahapan proses menganalisis konsep sistem, permasalahan serta keperluan yang akan dibuat.

2. Desain Sistem

Tahap desain sistem merupakan tahapan yang akan menghasilkan prototype atau desain lain yang diperlukan dalam pembuatan sistem.

3. Implementasi

Tahap implementasi merupakan tahapan dimana proses pengembangan software dilakukan. Implementasi pengembangan software dilakukan sesuai dengan rancangan yang telah dibuat sebelumnya.

4. $\quad$ Testing

Tahap testing merupakan tahapan pengujian pada sistem untuk menilai apakah software dapat bekerja sesuai dengan fungsionalitas yang diharapkan.

5. Perilisan

Tahap ini merupakan tahapan deployment agar user bisa mulai menggunakan software yang telah dibuat.

6. Pemeliharaan

Tahapan ini berfungsi untuk pemeliharaan sistem dan juga rutin melakukan pembaruan agar kinerja software tetap optimal.

\subsection{Metode waterfall}

Metode waterfall merupakan salah satu metodologi SDLC yang mana tahapan-tahapannya dilakukan secara berurutan. Hal itu berarti sebuah tahapan di metode waterfall tidak bisa dilakukan sebelum tahapan sebelumnya selesai. Jadi, untuk setiap tahapannya tidak boleh dikerjakan secara bersamaan. Metode ini juga bisa dibilang kurang fleksibel, karena prosesnya hanya satu arah saja seperti air terjun.

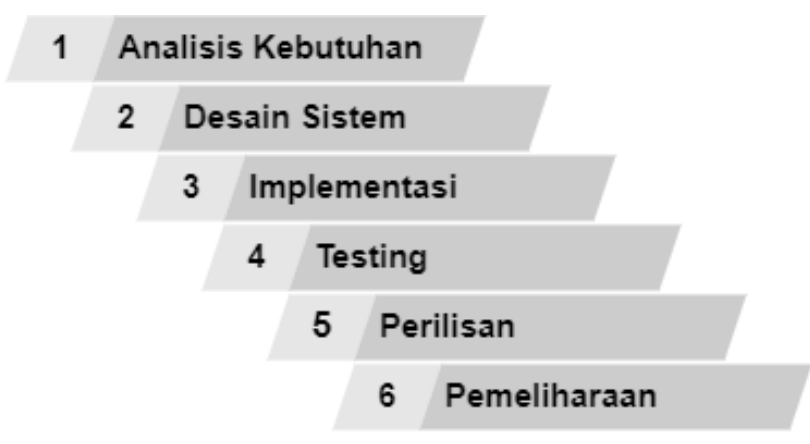

Gambar 1. Diagram Metode Waterfall

\subsection{Metode agile scrum}

Metode agile adalah salah satu metodologi SDLC yang berbasis pada incremental model dan iteratif. Agile merupakan sebuah metode pengembangan software dengan berbagai proses kecil yang berulang. Hal ini menjadikan metode agile cukup fleksibel akan perubahan ditengah proses pengembangan. Dalam penerapannya agile membutuhkan kerangka kerja yang mendukung konsep agile, salah satunya adalah scrum.

Scrum merupakan salah satu kerangka kerja yang bisa di implementasikan untuk mendukung konsep metode agile. Scrum berfungsi untuk membuat prinsip agile berwujud menjadi langkah-langkah. Hal yang penting di dalam scrum adalah sprint. Sprint ialah kegiatan yang memiliki durasi maksimal 30 hari yang terdiri dari beberapa aktifitas yaitu, sprint planning, daily scrum, sprint review dan sprint retrospective. 


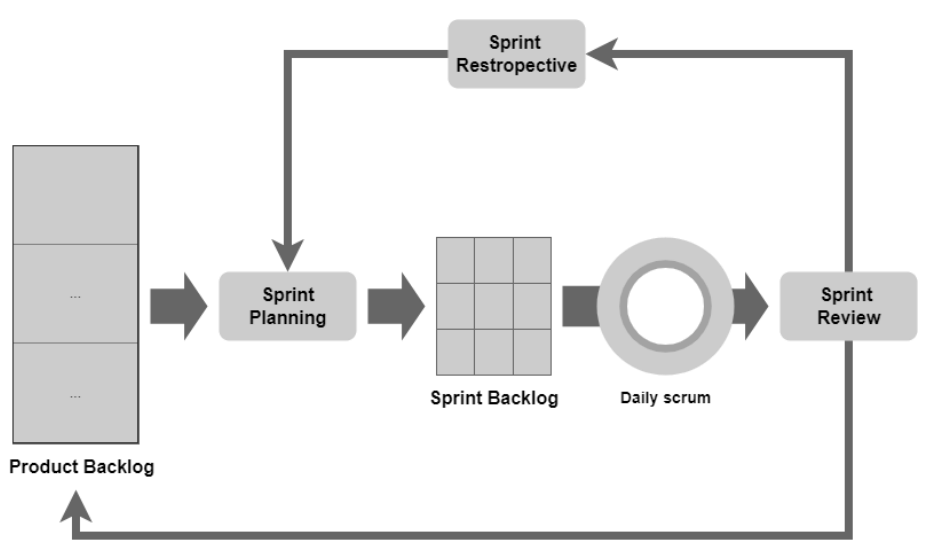

Gambar 2. Diagram Metode Agile Scrum

\subsection{Trello}

Trello merupakan sebuah aplikasi yang berfungsi sebagai alat kolaborasi antar tim dalam pengembangan proyek[10]. Salah satu fungsi trello adalah bisa melakukan pencatatan tentang list proses yang ingin dikerjakan dalam pengembangan proyek. Maka dari itu trello bisa berfungsi sebagai alat manajemen proyek di dalam metode agile scrum ini seperti pencatatan product backlog, sprint backlog dll. Selain itu trello juga bisa di akses via website dan aplikasi mobile.

\section{Metode Penelitian}

Penelitian ini membahas tentang implementasi pengerjaan proyek oleh PT Andromedia yang menggunakan agile scrum serta trello sebagai alat bantu kolaborasi tim. Scrum sendiri memiliki beberapa tahapan seperti:

A. Penentuan Product Backlog

Penentuan product backlog merupakan proses pengumpulan kebutuhan atau requirement yang dilakukan melalui daftar prioritas kebutuhan sistem[11].Tahapan ini dilakukan di awal proses sprint.

B. Penentuan Sprint Backlog

Penentuan sprint backlog merupakan tahapan dimana dilakukannya proses pemenuhan kebutuhan sesuai dengan daftar kebutuhan yang telah dibuat pada product backlog[12]

C. Daily Scrum

Daily Scrum merupakan pertemuan antar anggota tim yang dibatasi hanya selama 15 menit yang diadakan setiap harinya untuk tim pengembang mensikronisasikan segala aktifitas dan rencana yang akan dikerjakan selama 24 jam kedepan[13]. Daily scrum ini juga bisa menjadi diskusi ketika ada hambatan dalam proses pengembangan

D. Sprint review

Sprint review merupakan kegiatan dimana untuk merivew rangkaian sprint tersebut. Hasil dari sprint review merupakan sebuah product backlog yang telah diperbarui yang akan digunakan dalam proses sprint berikutnya[14].

E. Sprint retrospective

Sprint restrospective merupakan tahapan yang dilakukan setelah sprint berakhir yang tujuannya untuk mengevaluasi kinerja antar tim

\section{Hasil dan Pembahasan}

Pada implementasinya pengerjaan proyek dengan metode agile scrum dilakukan menggunakan bantuan trello sebagai alat manajemen proyeknya. Trello bisa diakses melalui website maupun dengan aplikasi mobile. Selain itu trello juga bisa diakses free maupun yang berbayar dengan tambahan fitur. Trello mempunyai beberapa fitur utama seperti Boards, Cards, Lists dan Menu[15].

Boards berfungsi untuk menampilkan manajemen proyek yang telah dibuat yang berisi tentang pengerjaan proyek tersebut. Cards merupakan komponen di dalam board dimana bisa di isi dengan berbagai informasi tentang kebutuhan proyek. Lists merupakan wadah dari card yang berfungsi memisahkan card sesuai dengan tahapannya, seperti jika sebuah card belum dikerjakan maka berada di list To Do, jika sudah maka card bisa dipindahkan di list Done. Fitur utama yang terakhir adalah menu yang fungsinya bisa melakukan konfigurasi seperti manajemen anggota tim, filter cards, manajemen riwayat dll.

Pada penelitian ini studi kasus yang dikerjakan adalah manajemen proyek untuk pembuatan sistem 
manajemen pelabuhan. Beberapa hal yang perlu dilakukan adalah seperti berikut:

4.1. Penentuan product backlog

Ada beberapa requirement atau kebutuhan untuk sistem manajemen pelabuhan ini. Kemudian, requirement tersebut dituangkan dalam kumpulan product backlog, seperti di tabel 1 berikut.

Tabel 1. Product Backlog

\begin{tabular}{|l|c|}
\hline \multicolumn{1}{|c|}{ Product Backlog } & $\begin{array}{c}\text { Sprint } \\
\text { ke }\end{array}$ \\
\hline $\begin{array}{l}\text { Admin mampu mengelola hak akses karyawan yang masuk } \\
\text { ke sistem }\end{array}$ & 1 \\
\hline Untuk login bisa menggunakan email dan password & 1 \\
\hline $\begin{array}{l}\text { Sebagai karyawan bisa menambah, mengedit dan } \\
\text { menghapus data kapal yang masuk mengirimka kontainer } \\
\text { dan yang keluar untuk melakukan pengiriman }\end{array}$ & 2 \\
\hline $\begin{array}{l}\text { Sebagai karyawan bisa mengetahui jumlah kapal dan } \\
\text { kontainer yang masuk serta perkembangannya dalam } \\
\text { bentuk grafik }\end{array}$ & 2 \\
\hline$\ldots$ & $\ldots$ \\
\hline$\ldots$ & $\ldots$ \\
\hline
\end{tabular}

\subsection{Penentuan sprint backlog}

Penentuan sprint backlog dilakukan sesuai dengan di sprint berapa dalam pengerjaan proyek. Dalam hal ini pengerjaan proyek memasuki sprint kedua yang artinya sprint backlognya seperti di tabel 2 berikut:

Tabel 2. Sprint Backlog

\begin{tabular}{|l|c|}
\hline \multicolumn{1}{|c|}{ Sprint Backlog } & $\begin{array}{c}\text { Sprint } \\
\text { ke }\end{array}$ \\
\hline $\begin{array}{l}\text { Sebagai karyawan bisa menambah, mengedit dan } \\
\text { menghapus data kapal yang masuk mengirimka kontainer } \\
\text { dan yang keluar untuk melakukan pengiriman }\end{array}$ & 2 \\
\hline $\begin{array}{l}\text { Sebagai karyawan bisa mengetahui jumlah kapal dan } \\
\text { kontainer yang masuk serta perkembangannya dalam } \\
\text { bentuk grafik }\end{array}$ & 2 \\
\hline
\end{tabular}

\subsection{Penentuan list to do}

Penentuan list to do berfungsi untuk membuat langkah nyata agar bisa mengimplementasikan sprint backlog yang telah ditentukan. List to do untuk sprint kedua ditunjukkan di tabel ke 3 .

Tabel 3. List To Do

\begin{tabular}{|l|}
\hline \multicolumn{1}{|c|}{ To Do } \\
\hline Merancang UI UX halaman pengiriman \\
\hline $\begin{array}{l}\text { Merancang UI UX untuk grafik perkembangan kontainer } \\
\text { yang masuk }\end{array}$ \\
\hline Implementasi CRUD pengiriman \\
\hline Implementasi grafik perkembangan kontainer \\
\hline
\end{tabular}

\subsection{Sprint}

Pada saat proses sprint berlangsung, card yang awalnya ada di list to do dipindahkan ke list in progress yang artinya sedang proses pengerjaan seperti yang ada di gambar 1 dan gambar 2 berikut 


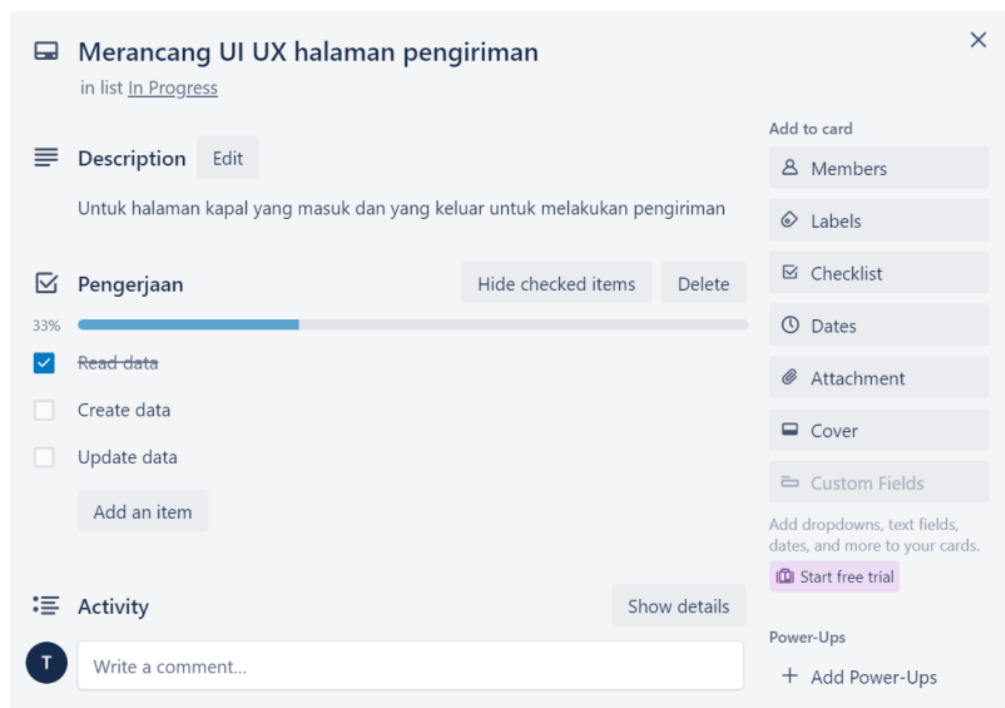

Gambar 3. Merancang UI UX halaman pengiriman

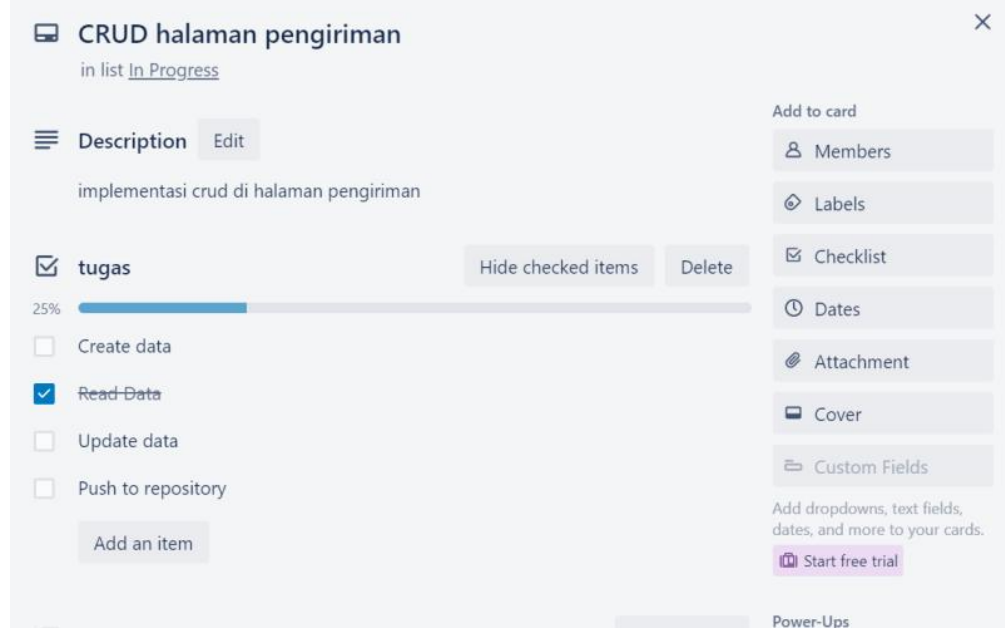

Gambar 2. CRUD Halaman pengiriman

Jika task atau card di list in progress sudah selesai dikerjakan maka akan dipindahkan ke list testing. List testing merupakan wadah bagi kumpulan card yang harus di lakukan pengetesan apakah sudah sesuai dengan yang diharapkan. Proses testing meliputi pengecekan alur sistem dan pengecekan dari sisi teknis apakah terdapat bug atau tidak. Jika hasil dari proses testing menunjukkan adanya kesalahan atau ketidaksesuaian dengan yang diharapkan maka akan masuk ke list revision, tapi jika hasilnya sesuai dengan yang diharapkan maka masuk ke list done.

\subsection{Sprint review dan sprint retrospective}

Pada pengerjaan proyek ini sprint review dan sprint retrospective dilakukan selama 1 minggu sekali yang dilakukan setelah sprint selesai. Meeting tersebut sekaligus membahas dan meriview sprint yang telah dilakukan selama seminggu kebelakang. Dalam meeting ini juga membahas tentang hal jika ada perubahan kebutuhan yang diminta oleh klien ditengah proses pengembangan. Sebagai contoh fitur login yang sudah dibuat di sprint pertama mengalami perubahan dikarenakan klien meminta agar login yang semula dengan email diganti menjadi dengan id karyawan, oleh karena itu task yang sudah berada di list done harus dipindahkan ke list revision, selain itu di dalam tasknya juga ditambahkan informasi tentang perubahan yang di inginkan seperti yang ada di gambar 3 berikut. 


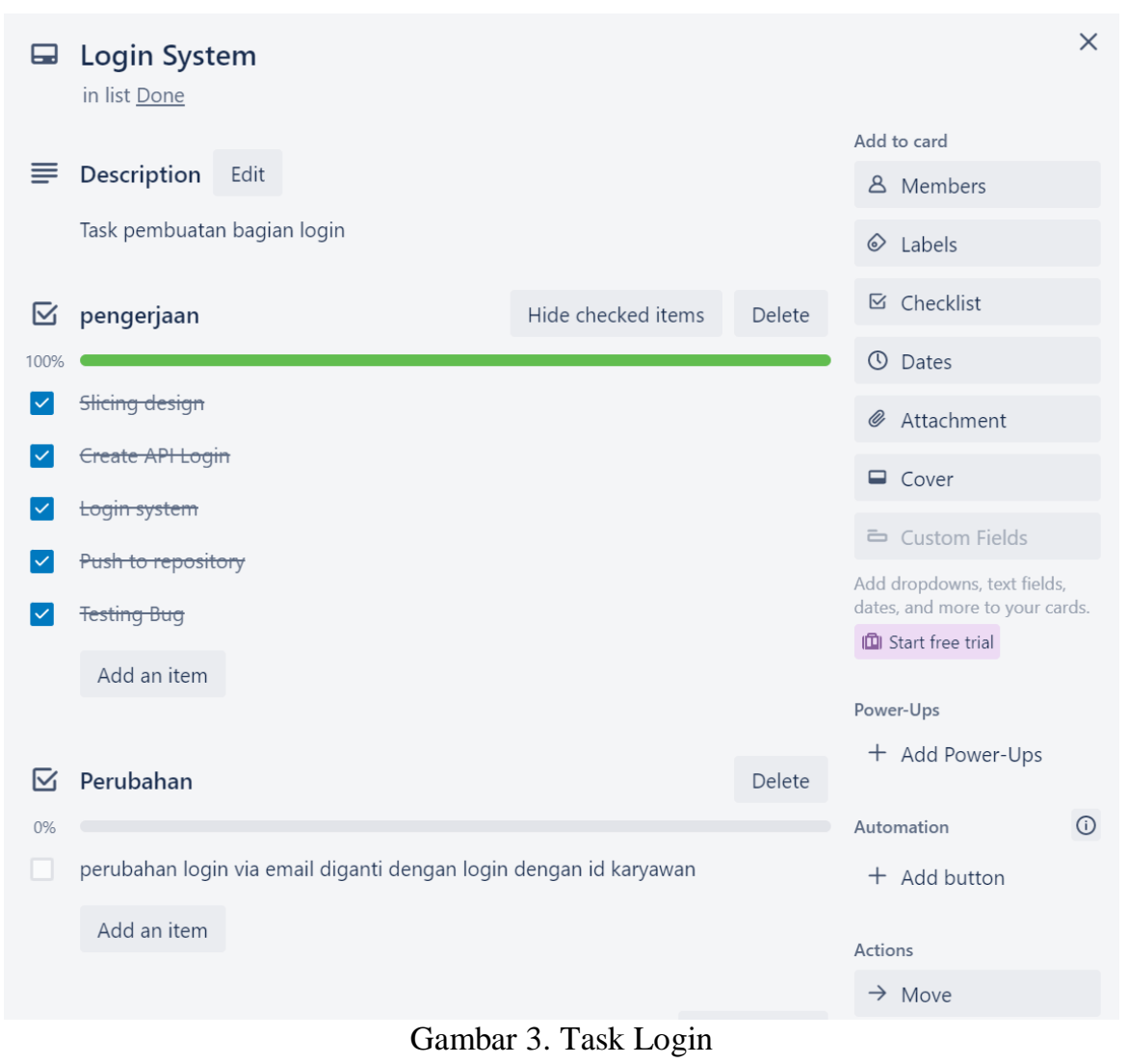

\section{Kesimpulan}

Implementasi metode agile scrum dengan menggunakan trello sebagai manajemen proyek di PT Andromedia bisa menjawab tantangan yang ada seperti perubahan kebutuhan atau requirement yang dilakukan ditengah proses pengembangan. Selain itu metode agile scrum juga cocok digunakan ketika mengerjakan proyek yang menginginkan hasil atau output bisa dilihat dengan cepat karena pengerjaan metode agile scrum dilakukan secara bertahap dan berulang.

\section{Daftar Pustaka}

[1] F. Marisa and T. G. Yuarita, "Perancangan Aplikasi Point of Sales (Pos) Berbasis Web Menggunakan Metode Siklus Hidup Pengembangan Sistem," J. Teknol. dan Manaj. Inform., vol. 3, no. 2, pp. 167-171, 2017, doi: 10.26905/jtmi.v3i2.1514.

[2] B. Kharisma and N. Santoso, "Pengembangan Aplikasi Manajemen Proyek Perangkat Lunak Kolaboratif Menggunakan Scrum," J. Pengemb. Teknol. Inf. dan Ilmu Komput. Univ. Brawijaya, vol. 4, no. 3, pp. 723-732, 2020.

[3] M. Faisal, "Rancang Bangun Sistem Informasi Housekeeping Inventory Dengan Metode Waterfall," $J$. Infortech, vol. 1, no. 1, pp. 28-34, 2019, doi: 10.31294/infortech.v1i1.6999.

[4] S. C. Fadilah, H. Rianto, and T. Hartati, "Implementasi Framework Code Iginter Menggunakan Metode Waterfall Pada Sistem Informasi Penjualan Pt . Supreme Jaya Abadi Jisicom," J. Inf. Syst. Informatics Comput., vol. 4, no. 1, pp. 134-140, 2020.

[5] K. Haryana, "Penerapan Agile Development Methods Dengan Framework Scrum Pada Perancangan Perangkat Lunak Kehadiran Rapat Umum Berbasis Qr-Code," J. Comput. Bisnis, vol. 13, no. 2, pp. 7079, 2019, doi: 10.5281/zenodo.3631045.

[6] D. A. Puspa Putri, "Rancang Bangun Media Pembelajaran Bahasa Arab Untuk Anak Usia Dini Berbasis Android," Technol. J. Ilm., vol. 10, no. 3, p. 156, 2019, doi: 10.31602/tji.v10i3.2230.

[7] T. Tohirin and S. R. Widianto, "Peran Trello dalam Adopsi Agile Scrum Pada Pengembagan Sistem Informasi Kesehatan," Multinetics, vol. 6, no. 1, pp. 32-39, 2020, doi: 10.32722/multinetics.v6i1.2763.

[8] P. Sistem, I. Aktiva, T. Dengan, and M. F. Scrum, "INTI NUSA MANDIRI," vol. 16, no. 1, pp. 7-14, 2021.

[9] M. R. Julianti, M. I. Dzulhaq, and A. Subroto, "Sistem Informasi Pendataan Alat Tulis Kantor Berbasis 
Web pada PT Astari Niagara Internasional,” J. Sisfotek Glob., vol. 9, no. 2, pp. 92-97, 2019.

[10] Y. Kosasih and A. Budi Cahyono, "Automation Testing Tool Dalam Pengujian Aplikasi The Point Of Sale," Tek. Inform., vol. 3, no. 2, 2020.

[11] M. Agarina, "Implementasi Scrum Agile Development Pada Sistem Informasi E -Mentor Di Kemahasiswaan IIB Darmajaya," vol. 15, no. x, 1978.

[12] H. Hutrianto and A. Putra, "IMPLEMENTASI SCRUM MODEL DALAM PENGEMBAGNAN APLIKASI pelAPORAN SAMPAH SEBAGAI WUJUD SMART CLEANING," JIPI (Jurnal Ilm. Penelit. dan Pembelajaran Inform., vol. 5, no. 1, p. 9, 2020, doi: 10.29100/jipi.v5i1.1552.

[13] R. A. Azdy and A. SN, "Implementasi Scrum Pada Pengembangan Software Terdistribusi," Semin. Nas. Inform. 2012, vol. 1, no. 2, pp. 32-37, 2012.

[14] F. Maulana and D. A. Ramadhan, "Pengembangan Aplikasi Android Patriot Pangan sebagai Sarana eParticipation untuk Sistem Ketahanan Pangan Nasional," J. Ilmu Komput. dan Agri-Informatika, vol. 7, no. 2, pp. 124-134, 2020, doi: 10.29244/jika.7.2.124-134.

[15] A. Anoesyirwan, H. Madiistriyatno, and S. Mutmainnah, "Peningkatan Kualitas Manajemen Publikasi Ilmiah Menggunakan Metode Agile," ADI Bisnis Digit. Interdisiplin J., vol. 1, no. 2 Desember, pp. 3139, 2020, doi: 10.34306/abdi.v1i2.99. 